Improving complex systems today : proceedings of the 18th ISPE International Conference on Concurrent Engineering, Massachusetts, USA 4-8 July 2011, pp327-335 Eds. Daniel D Frey, Shuichi Fukuda, Georg Rock.

\title{
Value Stream Analysis of Manufacturing Engineering New Product Introduction Processes
}

\author{
Malachy Maginness $^{\mathrm{a},}$, Essam Shehab $^{\mathrm{b}, 1}$ and Chris Beadle \\ ${ }^{\mathrm{a}, \mathrm{b}}$ Decision Engineering Centre, Manufacturing Department, Cranfield University, \\ College Road, Cranfield, Bedfordshire, MK43 0AL, United Kingdom \\ ${ }^{\mathrm{c}}$ Rolls-Royce plc., PO Box 31, Moor Lane, Derby, DE24 8BJ, United Kingdom
}

\begin{abstract}
This paper describes the use of a methodology for value stream mapping and analysis of Manufacturing Engineering New Product Introduction processes. The applicability and usefulness of the technique to process improvement in this domain is explored in a case study where the production system for a new component part is planned and proven. This analysis enables an improvement strategy for the Manufacturing Engineering process to be successfully outlined.
\end{abstract}

Keywords. New Product Introduction, Manufacturing Engineering, Aerospace, Lean

\section{Introduction}

Understanding current state conditions is the essential first step taken in any business seeking to improve how it performs its core processes. Successful process improvement strategies rely on acquiring rich, quantitative measures of the current state. The importance of such understanding is demonstrated in the measure and analysis phases of the widely used DMAIC (Define-Measure-Analysis-ImproveControl) model for processes improvement. Value stream mapping and analysis methodologies are well established tools for process improvement in physical manufacturing processes $[12,14]$. This paper describes the use of the value stream analysis to a novel area of the enterprise value chain: the transactional processes of Manufacturing Engineering New Product Introduction (NPI). A case study was carried out at a large aerospace manufacturer where Manufacturing Engineering

\footnotetext{
${ }^{1}$ E.Shehab, Manufacturing Department, Cranfield University, College Road, Cranfield, Bedfordshire, MK43 0AL, United Kingdom; Tel: +44 (0)1234 750111 x524; Email: e.shehab@scranfield.ac.uk
} 
(ME) performs a key role in developing and delivering the production system for the products and components developed by Design Engineering [13]. Value stream analysis methodology has recently been successfully applied to assist improvement efforts in the Design Engineering processes of this manufacturer [5]. The broader extension of the methodology as a standard for value stream analysis in transactional processes is explored here. Manufacturing Engineering can be understood as an information driven, transactional process aimed at creating physical production systems. This case study considers the processes associated with planning the production system for a particular component part. The complex geometry requires multiple manufacturing methods (for confidentiality these are identified as Method X and Method Y). The value proposition of Manufacturing Engineering is defining quality solutions to achieve design intent at required levels of cost and lead time. Lead times for physically creating all parts of the production system are a significant feature of the transactional process. A value orientated Manufacturing Engineering NPI process is one that can arrive at quality definitions of the method more quickly to enable rapid introduction of new products to market.

\section{Related Literature}

Techniques for evaluating value and waste in product development as a critical step toward improvement in information driven processes are emerging in literature [1-2, 4-11]. Parallels are drawn between the information products of product development and physical process products, and lean principles are extended across both domains $[6,10]$. The concept of 'value' in product development processes has been matured in a number of applications and remains consistent with user orientated definition of value in physical process domains [2, $6-8,10,12,14]$. 'Waste' is also considered. Information that waits in queues for the next processing activity is equated with physical inventory queues in machining systems [11]. The 'aspects' of value are further developed to stipulate those that define the product and production system and eliminate risk to the contrary. Tasks enabling value-add tasks to proceed (documentation) and those that are non-value adding (facilitating communication) are additionally proposed [4, 9].

A move towards a standard method for value stream analysis in the transactional product development process domain is evident [5, 9]. Two main areas of investigation are the metrics that are relevant for describing the transactional process flow, and the approach to visually map or represent that flow. Wasted time is advocated as a key improvement focus for lean product development [11]. To that end, the proportion of wasted time present in the lead (or elapsed) time for an activity is explored by distinguishing cycle (pure processing) time from waiting time (delays and interruptions). Furthermore, cycle time is decomposed into components of manual or automated time to indicate the degree of effort personally required from engineers to complete the process. The description of the value stream is completed by activities attributes which include the system tool used, those responsible and the inputs and output associated with each activity including format (the information flow) [5, 9]. Visual representation and mapping of the process flow is associated with the analysis approach. A 
Value Stream Analysis of Manufacturing Engineering New Product Introduction Processes 3

standard format that combines all the relevant information for value stream analysis in a singular representation has emerged [5]. The process flow is presented in 'activity boxes' named with a suitable description and accompanied by the attribute details and 'data-boxes' containing the metrics noted above. Information flows between activities are represented by arrows and the 'castle-wall' details respective iteration timelines. Crucially this approach is not yet applied to the Manufacturing Engineering transactional process domain [5].

\section{Method}

Data collection was carried out in three phases. In phase one the case study project was identified with the key stakeholder, the NPI lead in the relevant business area. The problem was bounded to a specific component example from a recent development project. A two hour workshop was conducted with input from a range of cross-functional representatives who were identified by the key stakeholder as relevant participants in the NPI process. The output was a high level map of 25 activities and information flows which was used to identify the boundaries of the end-to-end process. Post-it ${ }^{\circledR}$ notes were adopted as a flexible, interactive means of obtaining the depiction of this flow. This was later distributed among attendees and other stakeholders to obtain correction comments. The second phase consisted of a five day schedule of individual interviews with engineers. The initial map was used as a framework for developing a detailed map of the actual NPI process flow. The map was subject to numerous revisions as the data collection interviews continued. In its final version this map documented 107 activities and the information flows between them in a Role-Activity format [5]. The process map was presented in a one hour cross-functional workshop for validation. The final (five day) phase identified the key value stream for analysis during a workshop review of the detailed map with the main stakeholders. Further interviews were carried out and value stream metrics collected. A value stream map depiction was created and included activities and iterations identified in the detailed process flow map, along with the value stream metrics and time lines to indicate the specific activities that are revised in iteration loops. The final deliverable was the value stream mapping and metrics analysis and was presented to the key stakeholder for review and identification of future state improvement actions. All process flow and value stream map depictions were created in Microsoft Visio graphics software.

The main information source was the engineers who participated in the component NPI processes. These ranged from engineers with direct involvement in the activities to those at a business level of project management. Individual semistructured interviews conducted by the researcher were of approximately onehour's length each and were recorded by note taking, Dictaphone and transcripts. The question set was developed in line with the value stream metrics concepts discussed above [5] and piloted to verify comprehension and the recording technique. The first section of the question set defined an Activity Description as experienced by the interviewee (Table 1). This was structured around the SupplierInput-Process-Output-Customer (SIPOC) model in order to capture the information flow [3]. Capturing the system used in the activity considers the significant role 
computer aided design and manufacturing (CAD/CAM) now plays in engineering processes. The second section captured data consistent with the value stream metrics. Validation was achieved by corroboration with project planning literature and presentation of findings at workshops. A total of 11 interviews (excluding short sense-making conversations) and three workshops were completed.

Table 1. Collected Data Types

\begin{tabular}{|l|l|}
\hline Section 1: Activity Description & Section Two: Value Stream Metrics (Hours) \\
\hline Specialist Role/Activity Owner & Activity Lead Time (LT) \\
Activity Name & Cycle Time (CT) \\
System Used & Waiting/Delay Time (WT) \\
Number of Engineers involved & Manual Time (MT) \\
Work Output (including format) & Automated Time (AT) \\
Inputs (format) \& Suppliers & (LT =WT + CT) \\
Outputs (format) \& Customers & (CT = AT + MT) \\
\hline
\end{tabular}

\section{Findings}

\subsection{Description of the Value Stream}

Manufacturing Method X consists of stages of operations in which a sequence of tools forms simple material geometry into a shape approaching the complexity of the design intent. Manufacturing Method $\mathrm{Y}$ finishes the component made in Method X to a state that matches the design intent. Planning for Method X occurs simultaneously with Design Engineering processes and planning for Manufacturing Method Y uses certain of its definitions and physical parts to complete. As an intermediate process, planning of Method X has the potential to delay downstream processes and is compelled to complete within shorter lead times. The planning process uses a number of iterations that are a challenge to reducing lead time. Certain component geometry that is critical to the performance of the complete product is formed in the method. Physical trials (typically a total of three) are used to determine all aspects of tool geometry that influence the creation of a quality part that matches the design intent. It is for these reasons that a lean planning process for Manufacturing Method X is desirable and analysis was applied here.

The value stream map (Figure 1) depicts the particular value stream for planning Method X (including 25 activity steps) and begins with the first release of the component design model. Also recorded are the CAD/CAM systems used in defining the method. These include the company standard system used and a number of specialist alternatives. The final, intermediate and first stages are derived from the design model in a sequence that is the reverse of the production method. These definitions consist of the part shape expected at the end of each stage and the tool geometry to form it. All are created as CAD models. The final shape definition is evaluated for approval by the laboratory authority. Using the 


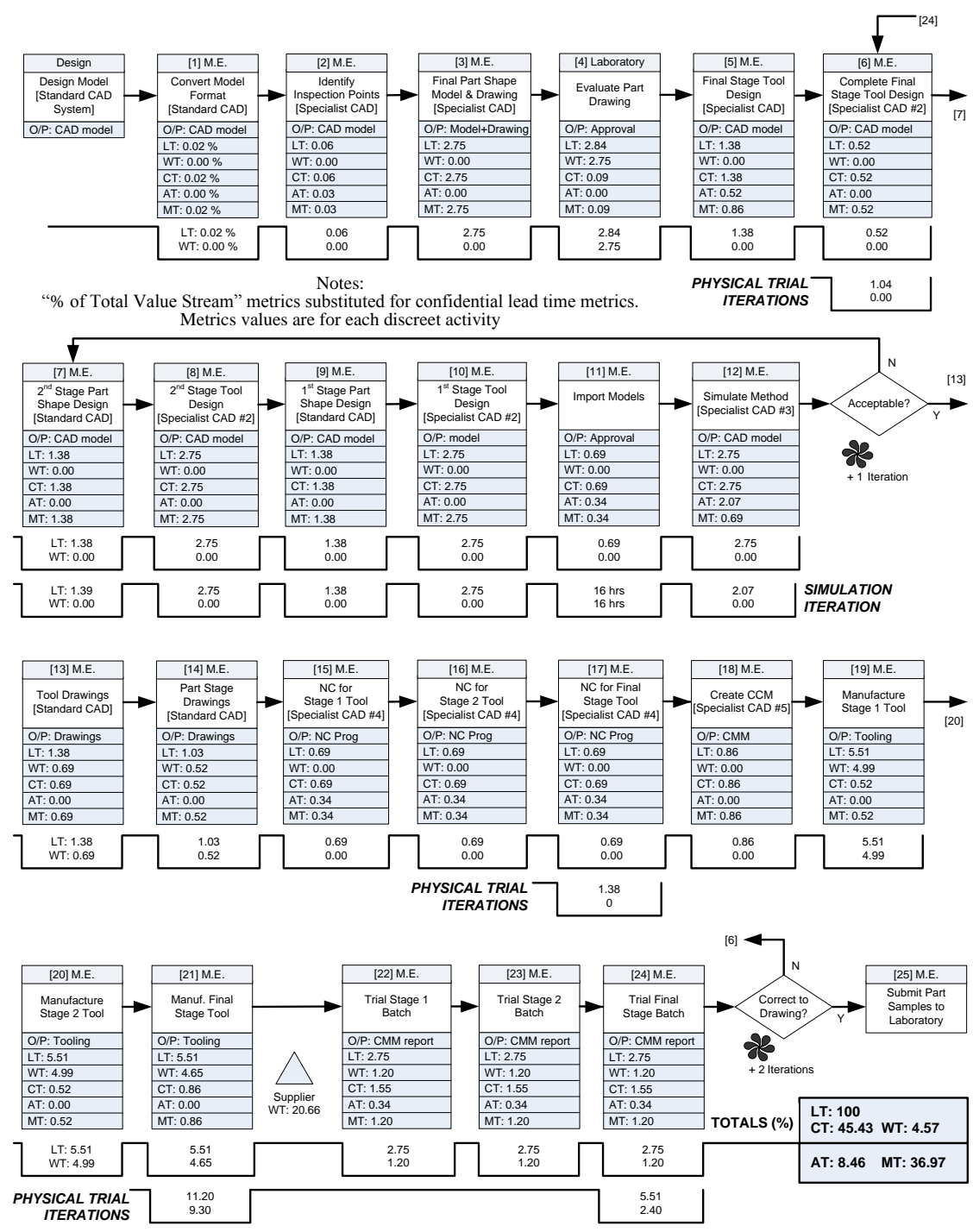

Figure 1. Manufacturing Engineering Value Stream for Method X Planning

models, the method is simulated virtually and alteration information fed back. Once acceptable, both part shape and tool geometry is described in technical drawings. Where necessary these are used to order tools and raw material in the external supply chain. Numerical Control (NC) and Coordinate Measurement Machine (CMM) sequences are generated from the models to drive in-house manufacture of tools and the inspection of parts. Upon availability of the material and tools, Method X is trialled, and CMM inspection conducted at each stage. Inspection measurements inform alteration requirements to ensure the part 
conforms to required geometry. These iteration loops are both transactional (reengineering the tool design and NC sequence) and physical (re-manufacturing). The value stream ends with submission of parts for inspection by the laboratory.

\subsection{Value Stream Analysis}

The value proposition was agreed with the key stakeholder to be that "a production process may be defined within manufacturing and inspection capability that captures the design intent of the component." At a high level of analysis the value add activity was calculated as almost $94 \%$ of the value stream's total lead time (Figure 2). The activities for stage definition (tool and part model creation and NC sequences) are directly value adding, as are the simulation and physical trials. These reduce the risk that the method will not create the required geometry. Activities enabling value adding examples include creating drawings that are formal definition of the planning, or model creation tasks begun in one CAD system prior to completion in another. Converting the format of the models is classed a non-value add activity and is associated with transportation waste although this claims an insignificant amount of the total lead time. However detailed analysis of the time metrics collected for each activity reveals the waiting time hazards that exist within the value adding activities. Total cycle time is less than half of the total value stream while 'waiting' accounts for 55\% of the critical path. Waiting is particularly evident in method trials $(30 \%$ of the total value stream). The reason attributed for this is accessing production equipment that is shared with full scale production. A wait for external supplies of material and tool items is also approximately $20 \%$ of the value stream. A wait for approvals is also evident. These are the key findings influencing future state process improvement.

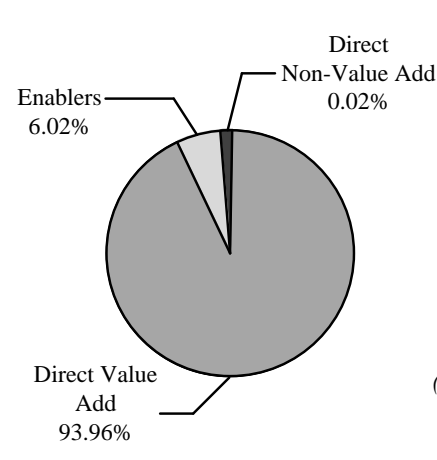

(1)

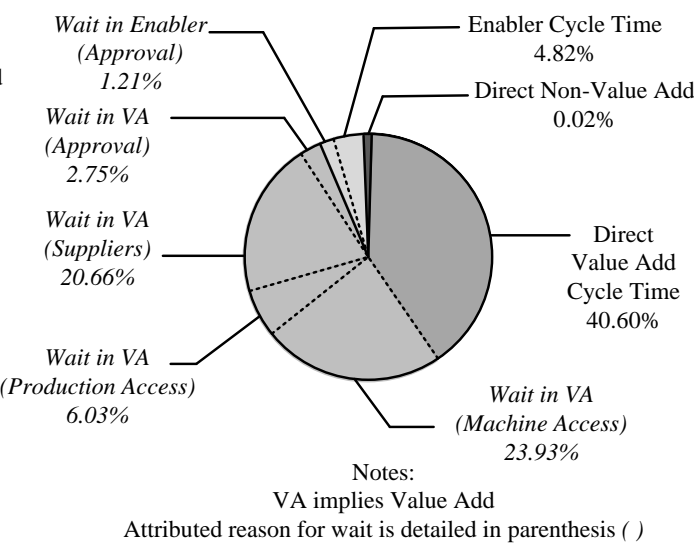

(2)
High Level Summary of Value Contribution

Figure 2. Value Stream Contributions in Cases 


\section{Discussion}

The usefulness of the value stream analysis and the metrics collected is verified by the ability of stakeholders to identify process improvement opportunities. The value stream mapping presented the process for planning Method X in a manner that is distinguished from wider Manufacturing Engineering process flow and allowed analysis in terms of constituent activities. The value adding, enabler and non-value adding tasks were identified in this value stream. Although made in a manner that was consistent with that established literature [9] and validated with the key stakeholder, this identification remains reliant on the analyst's interpretation. The activity metrics offered a more detailed and quantifiable level of analysis of the value stream that revealed the interaction of wastes with the value adding tasks. In particular the metrics revealed the areas of waiting that occur in the value adding planning process. A rapid process for defining a proven production process enhances the flexibility of NPI. Removing waiting wastes from the total lead time represents the obvious and quantifiable improvement targets. An outline of approaches to address this includes a better upfront planning process for securing both production equipment access and laboratory resource availability for evaluations. More advanced solutions will reduce the dependency on physical iterations with an enhanced virtual simulation capability. Iteration lead times here are notably shorter. An additional Pareto chart, populated by each activity, was considered by the stakeholder to be a powerful representation of the greatest lead time and waiting time contributors in the value stream. In this way the data is used to inform priority improvement strategies

Insights gained from this analysis are dependent on the quality of the original data. A detailed end-to-end map of the process that documents information flow and systems used to complete the identifiable engineering activities was necessary for initial comprehension of how value is added in the process. No such map preexisted for this case to use. It was created predominantly from the experiences of the engineers elicited from the interviews. Capturing all necessary opinion is important to the integrity of the results. For this, the support of the key stakeholder was crucial. Not only did this elicit the support needed within the business (access to engineers) but it also aided the ultimate verification that was required.

\section{Conclusions and Future Work}

A value stream analysis methodology has been applied in an investigation of the current state transactional processes of Manufacturing Engineering. The planning work associated with a specific production method served as the case study. The success of the approach is measured by the ability of the stakeholders to outline performance improvement targets. The process flow and value stream maps document an accurate end-to-end description of the actual current state process. This effort satisfies the measure and analysis phases of the DMAIC model of process improvement and enabled a number of measurable improvement opportunities to be outlined. Further work is necessary to define an accurate description of the future state. However, this case study has served to explore and 
illustrate the applicability of value stream analysis to the Manufacturing Engineering domain and this is the contribution made by this work.

\section{Acknowledgements}

The authors would like to thank the sponsors, Rolls-Royce plc, the Decision Engineering Centre in the School of Applied Sciences at Cranfield University, and the Engineering and Physical Sciences Research Council for supporting this work.

\section{References}

[1] Baines T, Lightfoot H, Williams GM, Greenough R. State-of-the-art in lean design engineering: A literature review on white collar lean. Proceedings of the Institution of Mechanical Engineers, Part B: Journal of Engineering Manufacture 2006; vol. 220, no. 9, pp. 1538-1547,

[2] Baines TS, Williams GM, Lightfoot H, Evans S. Beyond theory: An examination of lean new product introduction practices in the UK. Proceedings of the Institution of Mechanical Engineers, Part B: Journal of Engineering Manufacture 2007, vol. 221, no. 11, pp. 1593-1600. 2007

[3] Browning TR, Fricke E, Negele H. Key concepts in modeling product development processes. Systems Engineering 2005; vol. 9, no. 2, pp. 104-128

[4] Chase J. Value Creation in the Product Development Process. Masters thesis, Massachusetts Institute of Technology, Cambridge, 2001.

[5] Darwish M, Haque B, Shehab E, Al-Ashaab A. Value Stream Mapping and Analysis of Product Development (Engineering) Processes. Proceedings of the 8th International Conference on Manufacturing Research (ICMR 2010), Durham University, Sept 2010.

[6] Haque B. Lean engineering in the aerospace industry. Proceedings of the Institution of Mechanical Engineers, Part B: Journal of Engineering Manufacture 2003; vol. 217, no. 10, pp. 1409-1420.

[7] Haque B, Moore MJ. Measures of performance for lean product introduction in the aerospace industry. Proceedings of the Institution of Mechanical Engineers, Part B: Journal of Engineering Manufacture 2004; vol. 218, no. 10, pp. 1387-1398.

[8] Liker JK, Morgan JM. The Toyota Way in Services: The Case of Lean Product Development. Academy of Management Perspectives 2006; vol. 20, no. 2, pp. 5-20.

[9] McManus H. Product Development Value Stream Mapping (PDVSM) Manual. MIT Lean Aerospace Initiative, Cambridge, 2005.

[10] Reinertsen DG. Let it flow. Industrial Engineering (American Institute of Industrial Engineers) 2005; vol. 37, no. 6, pp. 40-45.

[11] Reinertsen DG. The Principles of Product Development Flow: Second Generation Lean Product Development. Celeritas Publishing 2009.

[12] Rother M, Shook J. Learning to See: Value-Stream Mapping to Create Value and Eliminate Waste. Lean Enterprise Institute: Brookline 2003.

[13] Ulrich KT, Eppinger SD. Product Design and Development 4th Ed. McGraw Hill 2008.

[14] Womack JP, Jones D. Lean thinking (2003 Edition), Simon \& Schuster 2003. 